REVISTA DE DERECHO UNED, NÚM. 16, 2015

\title{
LA COMUNIDAD ANDINA DE NACIONES (CAN)
}

\author{
THE ANDEAN COMMUNITY OF NATIONS
}

\author{
Ricardo Schembri CARRASQUilla (ULAC) \\ CaYetano NúÑEz Rivero (UNED)
}

Resumen: El presente trabajo analiza los diversos procesos de integración habidos en el área sudamericana, diferenciado las características políticas y económicas de los mismos, centrándose en Mercosur y la Comunidad Andina, señalando sus analogías y diferencias, incidiendo en la relación existente entre el derecho comunitario y el derecho interno de los Estados, estableciendo un proceso comparativo con el proceso de integración europeo.

Palabras clave: Integración, Mercosur, Comunidad Andina de Naciones, derecho comunitario, derecho estatal.

Abstract: His paper analyzes the various integration processes have taken place in the South American region, differentiated political and economic characteristics of them, focusing on Mercosur and the Andean Community, noting their similarities and differences, focusing on the relationship between Community law and domestic law of the State, by providing a comparative process with the process of European integration.

Keywords: Integration, Mercosur, CAN, Community law, state law.

Recepción original: 05/01/2015

Aceptación original: 27/01/2015

Sumario: 1. El Patrimonio Histórico de la Integración en América Del Sur. 2. Análisis Comparado Del Mercosur y La Comunidad Andina. 3. Derecho Comunitario Andino. 4. Las Constituciones Nacionales ante La Supranacionalidad. 5. Órganos de la CAN. 


\section{EL PATRIMONIO HISTÓRICO DE LA INTEGRACIÓN EN AMÉRICA DEL SUR}

El llamado "patrimonio histórico de la integración» de Latinoamérica y más concretamente de Suramérica, conformado por los diversos tratados y convenios de integración, comerciales y de complementación económica que se han suscrito y que se están ejecutando desde $1.960^{1}$ a nivel regional y subregional, ha venido construyendo una sólida base que permite visualizar hoy la pertinencia de una profundización de este proceso histórico, que se debate entre dos grandes tendencias: la del modelo librecambista o anglosajón que propugna por el libre comercio sin ningún grado de integración más allá de lo meramente mercantil y la del modelo comunitario o europeo, que aporta elementos meta-económicos e implica realizaciones políticas y sociales, a más de una gran profundización económica en busca del mercado único. Esta gama de tendencias genera lo que podemos denominar como Dimensiones de la Integración Latinoamericana.

El modelo librecambista busca esencialmente liberar el comercio de bienes y servicios y la circulación de capital a través de las inversiones, mediante la creación de áreas de libre comercio; el modelo comunitario es más profundo: no solamente libera la circulación de bienes, servicios y capitales, sino que además libera la circulación de personas, en las llamadas libertades comunitarias, que junto a las indicadas se ha propuesto adicionar la libertad de circulación de decisiones judiciales²; a más de ello, construye una unión aduanera o arancel externo común frente a terceros Estados; además armoniza o unifica las políticas macroeconómicas de los Estados Miembros (políticas fiscal, monetaria, crediticia, cambiaria); también crea la Comunidad como ente diferente a los Estados, con personería jurídica internacional y con órganos supranacionales; los Estados ceden competencias a esa Comunidad, quien las ejecuta; la Comunidad cuenta con presupuesto para financiar la ejecución de las políticas comunes, (p.ej. la política agrícola común en la Unión Europea); adicionalmente, emana de la Comunidad el derecho comunitario, el cual es de aplicación directa (es obligatorio para los Estados Miembros),

${ }^{1}$ El Tratado Constitutivo de la Asociación Latinoamericana de Libre Comercio ALALC (Montevideo, 1960), da inicio al proceso de integración de América Latina, el que además cuenta con profundas raíces históricas en los albores republicanos.

${ }^{2}$ DREYZIN DE KLOR, Adriana, Hacia la quinta libertad fundamental del MERCOSUR, En: MERCOSUL NO CENÁRIO INTERNACIONAL, DIREITO E SOCIEDADE, LUIS OTÁVIO PIMENTEL, Organizador, Curitiba, Brasil, Juruá Editora, 1.998, Volumen 1, Págs. 17 y ss. 


\section{La COMUNidAd ANDina de Naciones (CAN)}

efecto directo (produce efectos vinculantes ante la población de los Estados Miembros) y prima sobre el derecho nacional (la norma comunitaria hace inaplicable la norma nacional que le sea contraria); finalmente, la Comunidad genera importantes efectos políticos: ciudadanía europea, elección popular directa del Parlamento.

No se trata necesariamente de modelos antagónicos pero tampoco de modelos agonales per se. Pueden ser o no modelos compatibles o completamente excluyentes, lo cual depende del acierto con que se vayan aplicando, del contexto económico- social en el que se apliquen, de la perspectiva histórica y política que se tenga por los gobernantes, de los intereses que se manejen abierta o soterradamente en estos procesos.

Sin embargo, es importante destacar que un país o un bloque puede ser parte de múltiples tratados de libre comercio con otros Estados o bloques (todos los que quiera), en tanto que sólo puede pertenecer a una Comunidad, por los mayores y más profundos compromisos que ésta implica.

Los tratados, organismos y esquemas de integración actualmente vigentes en América del Sur, entendiendo por tal aquellos que tienen entre sus miembros sólo a países suramericanos, son los siguientes: el Mercado Común del Sur MERCOSUR, la Comunidad Andina de Naciones CAN, el Tratado MERCOSUR-CAN, la Organización del Tratado de Cooperación Amazónica OTCA, la Iniciativa para la Integración de la Infraestructura Regional Suramericana IIRSA y la Unión de Naciones Suramericanas UNASUR, sucesora de la Comunidad Suramericana. A ello se suman algunas empresas públicas suramericanas, ya constituidas o en proceso de conformación, cuáles pueden ser, entre otras, TELESUR, el Banco del Sur y PETROSUR.

La voluntad política de los Jefes de Estado suramericanos en pro de la integración actuará precisamente como elemento que debe lograr, de manera constante, el flexibilizar el arco de la integración en América del Sur; precisamente la Unión de Naciones Suramericanas UNASUR se erige como ese arco coordinador de los esfuerzos integracionistas suramericanos, que permitirá dar una mayor o menor gradualidad a la convergencia de los actuales tratados, organismos y mecanismos de integración del subcontinente, coordinar políticamente el proceso, unificar criterios y visiones, estimular la cooperación y el actuar conjunto de los diversos órganos de la integración suramericana. En otras palabras, se trata de dar continuidad institucional a estos pero acompañados por un nuevo ente de coordinación política, la UNASUR. 


\section{ANÁLISIS COMPARADO DEL MERCOSUR Y LA COMUNIDAD ANDINA}

El MERCOSUR y la COMUNIDAD ANDINA se erigen en la actualidad como los dos principales acuerdos de integración subregional vigentes en América Latina; este aserto nos lleva a analizar y comparar sus principales características institucionales.

En primer lugar, se trata de dos tratados suscritos en el marco de la Asociación Latinoamericana de Integración ALADI, la que de conformidad con el Tratado de Montevideo de 1.980 (TM80), permite que los Estados Miembros de ese organismo puedan pactar entre algunos de ellos acuerdos más profundos, que no son aplicables a los otros miembros de ALADI; son los llamados Acuerdos de Alcance Parcial (AAP):

"Los acuerdos de alcance parcial son aquellos en cuya celebración no participa la totalidad de los países miembros y propenderán a crear las condiciones necesarias para profundizar el proceso de integración regional mediante su progresiva multilateralización.

"Los derechos y obligaciones que se establezcan en los acuerdos de alcance parcial regirán exclusivamente para los países miembros que los suscriban o que a ellos adhieran» (art. 7 TM80).

Los Acuerdos ALADI de Alcance Parcial pueden ser comerciales, de complementación económica, agropecuarios, de promoción del comercio o adoptar otras modalidades (art. 8 TM80).

El Tratado de Asunción (1.991), constitutivo del Mercado Común del Sur «MERCOSUR», establece en el preámbulo su vocación latinoamericanista: "CONSCIENTES de que el presente Tratado debe ser considerado como un nuevo avance en el esfuerzo tendiente al desarrollo en forma progresiva de la integración de América Latina, conforme al objetivo del Tratado de Montevideo 1.980 ". La Comunidad Andina se define a sí misma como un Acuerdo Subregional («Acuerdo de Integración Subregional Andino») y puntualiza también su proyección latinoamericana: "El presente Acuerdo tiene por objetivos promover el desarrollo equilibrado y armónico de los Países Miembros en condiciones de equidad, mediante la integración y la cooperación económica y social; acelerar su crecimiento y la generación de ocupación; facilitar su participación en el proceso de integración regional, con miras a la formación gradual de un mercado común latinoamericano» Art. 1 Acuerdo de Cartagena). Así, pues, se trata de dos acuerdos subregionales (AAP) de ALADI, ambos con vocación latinoamericanista.

Ambos bloques económicos también se identifican por contar con personalidad jurídica internacional, característica ésta que no es 


\section{La COMUnidad ANDina de Naciones (CAN)}

esencial a un bloque económico; así, por ejemplo, en tanto la Unión Europea cuenta con personería jurídica internacional, el NAFTA no la tiene, no obstante su indudable importancia económica. ${ }^{3}$ El artículo 34 del Protocolo de Ouro Preto confiere al MERCOSUR personalidad jurídica internacional («El MERCOSUR tendrá personalidad jurídica de Derecho Internacional»), lo cual a su vez se establece en el artículo 48 del Acuerdo de Cartagena ${ }^{4}$ para la COMUNIDAD ANDINA ( $L$ La Comunidad Andina es una organización subregional con personería o personalidad jurídica internacional»). Esta es una clara manifestación de la voluntad de los Estados miembros del MERCOSUR y de la COMUNIDAD ANDINA de tener una presencia internacional como bloques económicos.

En cuanto hace relación a su organización institucional, los dos entes internacionales presentan fundamentales diferencias. La primera que se pone presente es cuantitativa: la organización institucional de la COMUNIDAD ANDINA es enorme comparada con la del MERCOSUR. Establece el artículo 5 del Acuerdo de Cartagena que la Comunidad Andina la conforman los Estados miembros y los órganos del Sistema Andino de Integración; a su vez, el artículo 6 de dicho tratado determina que son órganos del Sistema Andino de Integración: el Consejo Presidencial Andino; el Consejo Andino de Ministros de Relaciones Exteriores; la Comisión de la Comunidad Andina; la Secretaría General de la Comunidad Andina; el Tribunal de Justicia de la Comunidad Andina; el Parlamento Andino; el Consejo Consultivo Empresarial; el Consejo Consultivo Laboral; la Corporación Andina de Fomento; el Fondo Latinoamericano de Reservas; el Convenio Simón Rodríguez, los convenios sociales que se adscriban al Sistema Andino de Integración, la Universidad Andina Simón Bolívar, los Consejos Consultivos que establezca la Comisión y los demás órganos e instituciones que se creen en el marco de la integración subregional andina. El Protocolo de Ouro Preto establece la institucionalidad ac-

${ }^{3}$ Es ésta también una manifestación de la intensidad de integración que los Estados pactan, pues en tanto algunos tratados sólo buscan la liberación del comercio en sentido amplio, otros son más ambiciosos en sus objetivos y pretenden la creación de un mercado único con libre circulación de todos los factores de producción, arancel externo unificado, armonización de políticas macroeconómicas, implementación y ejecución de políticas comunes, unificación del derecho, todo ello con la activa participación de autoridades supranacionales que se crean por los Estados: es el fenómeno comunitario. Entre los dos extremos existen diversas manifestaciones jurídicas y económicas.

${ }^{4}$ Todas las citas del Acuerdo de Cartagena lo son de la codificación hecha de éste mediante la Decisión 406 de junio 25 de 1.997 de la Comisión de la Comunidad Andina, en la que se incluye el Protocolo de Trujillo (1.996), por el cual se realizaron importantes reformas a dicho ente. 
tual del MERCOSUR, la que se conforma con los siguientes órganos (art. 1): el Consejo del Mercado Común, el Grupo Mercado Común la Comisión de Comercio del MERCOSUR, el Parlamento del MERCOSUR, el Foro Consultivo Económico - Social y la Secretaría Administrativa del MERCOSUR. Otra diferencia notable hace relación a la calidad de los miembros o funcionarios de esos órganos, pues en tanto en la Comunidad Andina existen muchos funcionarios permanentes de la Comunidad o de los órganos del Sistema Andino de Integración (los de la Secretaría General, los del Tribunal, los del Convenio Andrés Bello, los del Fondo Latinoamericano de Reservas, los de la Corporación Andina de Fomento, los de la Universidad Andina), cuyos sueldos deben ser pagados por el respectivo ente, en el MERCOSUR la mayoría de sus órganos se conforman por funcionarios nacionales, es decir por funcionarios que no lo son del MERCOSUR en forma permanente y en consecuencia de ello no implican gastos de funcionamiento para ese organismo; por supuesto en la Comunidad Andina hay órganos conformados por funcionarios nacionales (Consejo Presidencial Andino, Consejo Andino de Ministros de Relaciones Exteriores y Comisión) y en el MERCOSUR cuentan con un órgano de funcionarios permanentes (la Secretaría Administrativa), pero sí es destacable que los gastos de funcionamiento de la COMUNIDAD ANDINA son superiores a los del MERCOSUR por contar con mayor cantidad de órganos y funcionarios permanentes y propios; recuérdese que en buena medida la Comunidad Andina se ha inspirado en el modelo europeo de organización comunitaria.

Otro aspecto del análisis institucional aquí propuesto hace relación a la naturaleza jurídica del MERCOSUR y de la COMUNIDAD ANDINA pues ambos son organismos de integración, pero con diversos acentos; el MERCOSUR tiende a ser un organismo más internacional que la COMUNIDAD ANDINA y ésta tiende a ser un organismo más supranacional y en consecuencia de ello los órganos del MERCOSUR son más marcadamente intergubernamentales, mientras que en la COMUNIDAD ANDINA conviven órganos supranacionales con órganos intergubernamentales. Definimos a un órgano como supranacional en la medida en que los Estados miembros le hayan cedido en el respectivo tratado competencias normativas, jurisdiccionales o administrativas, propias de la función estatal y siempre que las actuaciones correspondientes de esos órganos vinculen $\mathrm{u}$ obliguen a los Estados miembros y a sus habitantes; pues bien, los órganos de la Comunidad Andina que se pueden definir propiamente como supranacionales son el Consejo Presidencial Andino, el Consejo Andino de 


\section{La COMUnidad ANDina de Naciones (CAN)}

Ministros de Relaciones Exteriores, el Parlamento Andino ${ }^{5}$, la Comisión de la Comunidad Andina, el Tribunal de Justicia de la Comunidad Andina y la Secretaría General de la Comunidad Andina; los demás órganos del Sistema Andino de Integración son de naturaleza intergubernamental. Por su parte, el Protocolo de Ouro Preto define en su artículo 2 que los órganos del MERCOSUR con capacidad decisoria son el Consejo Mercado Común, el Grupo Mercado Común y la Comisión de Comercio del MERCOSUR y que estos son «de naturaleza intergubernamental».

Directamente derivado de este planteamiento surge el análisis de las normas jurídicas que se producen en el seno del MERCOSUR y en la COMUNIDAD ANDINA, pues mientras las normas de los órganos supranacionales andinos son de efecto directo, aplicación directa y primacía sobre el derecho nacional, las normas que emanan de los órganos del MERCOSUR, deben ser incorporadas a los respectivos ordenamientos jurídicos nacionales, lo que implica la ausencia de supranacionalidad en el MERCOSUR; también en este tópico la COMUNIDAD ANDINA sigue más de cerca al modelo comunitario europeo. En efecto, el Protocolo de Ouro Preto determina que las Decisiones del Consejo del Mercado Común, las Resoluciones del Grupo Mercado Común y las Directivas de la Comisión de Comercio del MERCOSUR, esto es los órganos con capacidad decisoria (art. 2), son «obligatorias para los Estados Parte» (arts. 9, 15 y 20) lo cual implica que producen efectos jurídicos frente a éstos sin necesidad de ratificación adicional alguna: es la característica del efecto directo; a su vez, el tenor literal de los artículos 25 y 42 de dicho Protocolo indican claramente que las normas emanadas de los órganos del MERCOSUR deben ser incorporadas al derecho interno de cada País miembro, de donde se deriva que no producen efecto automático ante los habitantes, que esas normas no los obligan hasta tanto sean incorporadas a la legislación nacional y que las normas del MERCOSUR no priman sobre el derecho nacional ni lo hacen automáticamente inaplicable si es contrario a la norma comunitaria. Art. 25;»las normas emanadas de los órganos del MERCOSUR previstos en el artículo 2 de este Protocolo tendrán carácter obligatorio y, cuando sea necesario, deberán ser incor-

\footnotetext{
${ }^{5}$ No basta la elección popular directa para medir el grado de multinacionalismo, supranacionalidad e integración: a más de ello se requiere que el Parlamento tenga facultades colegisladoras en la producción del derecho supranacional (usualmente compartidas con el Consejo de Ministros, el principal legislador supranacional); que tenga control político sobre el ejecutivo supranacional (con voto de confianza para constituirlo y voto de censura para disolverlo); y que sea la máxima autoridad supranacional en materia presupuestal, lo que presupone además la existencia de un importante presupuesto supranacional, alimentado con ingresos supranacionales propios.
} 
poradas a los ordenamientos jurídicos nacionales mediante los procedimientos previstos por la legislación de cada país.» (art. 42). El ordenamiento jurídico de la COMUNIDAD ANDINA se compone en sentido amplio por las Directrices del Consejo Presidencial Andino (art. 11 Acuerdo de Cartagena), las Decisiones del Consejo Andino de Ministros de Relaciones Exteriores (art. 17 id.), las Decisiones de la Reunión Ampliada del Consejo de Ministros de Relaciones Exteriores con la Comisión (art. 20 id.), las Decisiones de la Comisión (art. 21 id.), las Decisiones de la Comisión Ampliada con Ministros de sectores específicos (art. 25 id.), las sentencias del Tribunal de la Comunidad Andina y las Resoluciones de la Secretaría General; las normas comunitarias andinas de carácter general son de efecto directo, aplicación directa y primacía sobre el derecho nacional, lo cual implica que son vinculantes para los Estados miembros sin necesidad de ratificación (efecto directo), que obligan a los habitantes sin que se requiera su incorporación al derecho nacional (aplicación directa) y que hacen inaplicable al derecho interno que le sea contrario (primacía sobre el derecho nacional); al igual que ocurrió en los inicios de la Comunidad Europea, éstas características del derecho comunitario andino no están expresamente consagradas en el Acuerdo de Cartagena, pero la jurisprudencia del Tribunal de la Comunidad Andina, directamente inspirada en la europea, la jurisprudencia nacional y la práctica de los Estados las han ido decantando y hoy tienen plena vigencia, si bien es verdad que las normas comunitarias andinas no presentan el grado de desarrollo, la extensión en varios cuerpos normativos, la eficacia y la dinámica social del derecho comunitario europeo. Así pues, las normas derivadas en el MERCOSUR tienen efecto directo pero no son de aplicación directa ni priman sobre el derecho nacional, en tanto que las normas derivadas de la COMUNIDAD ANDINA son de efecto directo, aplicación directa y priman sobre el derecho interno.

Simultáneamente con el análisis de la naturaleza jurídica del MERCOSUR y de la COMUNIDAD ANDINA, de sus órganos y del derecho producido por estos, es necesario tener en cuenta la forma en que se adoptan las decisiones en los órganos correspondientes. En este aspecto las dos subregiones se identifican entre sí y se alejan por ahora de la tendencia predominante en la Unión Europea, puesto que en los esquemas integracionistas suramericanos hay plena igualdad jurídica dado que todos los Estados tienen representación paritaria en los órganos, es decir que no existe un voto ponderado para los Estados, que en cierta medida atienda a su capacidad económica (la que además se traduce en mayores aportes presupuestales a la Comunidad), ni diferencias en el número de parlamentarios atendiendo a su 


\section{La COMUnidad ANDina de Naciones (CAN)}

población. ${ }^{6}$ Sin embargo esto podría estar empezando a cambiar, pues por ejemplo en el Protocolo de Montevideo (2005) que creó el Parlamento del MERCOSUR se estableció una representación igualitaria de parlamentarios delegados por los Congresos nacionales al Parlamento de integración, pero también se previó el instaurar la elección popular directa de los parlamentarios del MERCOSUR en el año 2011, para lo cual se pactó una representación proporcional a la población, fórmula muy vaga que seguramente generará difíciles negociaciones en el futuro y que en todo caso empieza a romper la tradición suramericana (y latinoamericana) de igualdad jurídica de los Estados en los organismos de integración.

Se diferencian la COMUNIDAD ANDINA y el MERCOSUR en que en la primera algunos de sus órganos pueden tomar decisiones por mayoría, como es el caso de la Comisión y de la Comisión Ampliada (arts. 25 y 26 Acuerdo de Cartagena) o se trata de órganos supranacionales unipersonales, como lo es la Secretaría General; en el Protocolo de Ouro Preto, por el contrario, se establece que todas las decisiones se deben adoptar por consenso y con la presencia de todos los Estados parte (art. 37). Lo importante a destacar en conclusión es que en la COMUNIDAD ANDINA y en MERCOSUR existen órganos permanentes, con capacidad de generar derecho derivado, esto es, normas que se derivan jurídicamente de los tratados fundacionales o constitutivos, a diferencia de lo que ocurre en tratados de naturaleza librecambista (Grupo de los Tres, Tratado de Libre Comercio de América del Norte o "NAFTA«, Tratado de Libre Comercio EE. UU. con Chile, Proyecto TLC EE. UU., con países andinos, proyecto ALCA, proyecto tratado libre comercio Unión Europea - Comunidad Andina, entre otros) en los que no hay órganos permanentes y en ningún caso hay derecho derivado, ni ningún grado de supranacionalidad.

${ }^{6}$ Los Estados miembros de la Unión Europea tienen un voto desigual o una presencia desigual en algunos de los órganos comunitarios, como ocurre en el Consejo, en el que toma algunas de sus decisiones por unanimidad, caso en el cual la abstención de un Estado no impide la adopción de los acuerdos por unanimidad, o por mayoría absoluta en los más de los casos, evento éste en el que hay un voto ponderado para los Estados, en el que los Estados de mayor población y mayor PIB tienen un mayor número de votos. La Comisión europea, órgano ejecutivo de la Comunidad, independiente de los gobiernos nacionales, estaba compuesta en forma desigual pues los Estados grandes contaban con dos comisarios en tanto que los más pequeños en su economía tenían uno, si bien se trata de funcionarios independientes y autónomos ante los Estados; hoy son 27 Comisarios, uno de cada país, quienes adoptan sus decisiones por unanimidad o por mayoría, En el Parlamento Europeo, el que es elegido directamente la representación es más directamente proporcional al número de habitantes: a mayor número de habitantes, mayor número de parlamentarios, aunque no de una manera exacta. 
Una muy notoria diferencia que existía entre el MERCOSUR y la COMUNIDAD ANDINA era la de los mecanismos de solución de controversias, pues mientras la CAN contaba con un Tribunal supranacional para la solución de controversias y la interpretación del Derecho Comunitario, inspirado en el Tribunal comunitario europeo, el MERCOSUR carecía de éste y aplicaba el arbitraje como mecanismo; sin embargo, a partir del Protocolo de Olivos (2002), el MERCOSUR también institucionalizó su Tribunal, con sede en Asunción, aunque éste no desnaturalizó la esencia arbitral del sistema de solución de controversias del MERCOSUR pues este Tribunal Permanente revisa los laudos de los Tribunales arbitrales, designados en cada controversia de la lista de árbitros. Se asemejan entonces hoy en que tanto en la CAN como en el MERCOSUR la controversia inicialmente se lleva ante un órgano no jurisdiccional (Grupo Mercado Común en el MERCOSUR; Secretaría General en la CAN) y de no hallarse solución, pasa al Tribunal permanente respectivo (Quito o Asunción), aunque el tribunal de la CAN es supranacional y el del MERCOSUR es arbitral y además en el MERCOSUR las partes pueden optar por adelantar su controversia utilizando los mecanismos de la Organización Mundial del Comercio OMC. El Tribunal de Quito (CAN) es un tribunal permanente, de naturaleza supranacional y jurisdicción obligatoria para la solución de controversias derivadas del Acuerdo de Cartagena, cuyas sentencias obligan a los Estados miembros, el cual se creó mediante el llamado Tratado del Tribunal (Cartagena, 28 de mayo de 1.979), está conformado por un magistrado de cada país y tiene como funciones esenciales el conocer de las acciones de incumplimiento y de nulidad y de la interpretación prejudicial ${ }^{7}$. En el marco del MERCOSUR se debatió ampliamente en torno a la creación de un tribunal permanente para sustituir el sistema de solución de controversias que era regulado por el Protocolo de Brasilia de diciembre 17 de 1.991, en el que, cuando se presentaba una controversia entre Estados miembros, se iniciaban negociaciones directas, se pasaba a la intervención del Grupo Mercado Común y se finalizaba, de no funcionar los mecanismos anteriores, con la convocatoria de un Tribunal arbitral cuya jurisdicción y decisión eran obligatorias para los Estados en controversia; hoy la controversia se di-

\footnotetext{
${ }^{7}$ En el Protocolo de Cochabamba, suscrito el 28 de mayo de 1996, se refuerza el acceso de los particulares a la acción de nulidad, se da acceso a los particulares a la acción de incumplimiento y se establece que la sentencia del Tribunal comunitario andino les sirve de título legal para solicitar ante el juez nacional la indemnización de daños y perjuicios correspondiente, se dan facultades arbitrales al Tribunal en causas distintas a las comunitarias andinas (como fuente rentística para el Tribunal de Quito), se crea el recurso de omisión por inactividad de los órganos comunitarios el que se otorga a los particulares y a otros órganos comunitarios y se crea la jurisdicción laboral del Tribunal para los conflictos entre los funcionarios comunitarios el sistema andino de integración.
} 


\section{La COMUNidAd ANDina de Naciones (CAN)}

rime primero en el grupo mercado Común de no hallarse solución pasa a un Tribunal Arbitral, cuyo laudo puede ser susceptible de recurso ante el Tribunal de Revisión.

Se destaca como diferencia entre los dos acuerdos subregionales el trato jurídico contemplado para los Estados Miembros; si bien ambos son Acuerdos ALADI y el Tratado de Montevideo de 1.980 contempla en su capítulo III (arts. 15 a 23) el "Sistema de apoyo a los países de menor desarrollo económico relativo", en el que se consagran para tal efecto los principios de no reciprocidad y de cooperación comunitaria, lo cierto es que el MERCOSUR eliminó la no reciprocidad y el trato preferencial para los países de menor desarrollo económico relativo, en tanto que la COMUNIDAD ANDINA los mantiene e implementa. En efecto, el Tratado de Asunción (marzo 26 de 1.991), constitutivo del MERCOSUR establece en su artículo 2 que «el Mercado Común estará fundado en la reciprocidad de derechos y obligaciones de las partes», lo cual se atenúa algo pero en muy pequeña medida con el artículo 6 y el anexo I del tratado en los que se concedió a Paraguay y Uruguay un plazo de desgravación arancelaria de un año adicional al término con que contaban Brasil y Argentina; se establece en el artículo 8 un compromiso de preservar los compromisos adquiridos hasta la constitución del MERCOSUR, incluido el de ALADI, pero en los mecanismos allí mismo establecidos para tal efecto no se menciona nada en relación con el trato preferencial a Países de menor desarrollo relativo; simplemente Uruguay y Paraguay renunciaron a ese trato. También ello se refleja en materia presupuestal, pues los Estados miembros aportan en partes iguales el presupuesto para atender los gastos de funcionamiento de la Secretaría Administrativa del MERCOSUR y aquellos que disponga el Grupo Mercado Común (art. 45 Protocolo de Ouro Preto). En la COMUNIDAD ANDINA, por el contrario, se contempla un Régimen Especial para Bolivia y Ecuador (capítulo XIII del Acuerdo de Cartagena, arts. 121 a 138), atinente a la armonización de políticas económicas, coordinación de planes de desarrollo, política industrial, política comercial, arancel externo común, cooperación financiera y asistencia técnica; a más de ello, si bien el Acuerdo de Cartagena no lo regula directamente, el art. 22 literal i de dicho Acuerdo establece que la Comisión debe aprobar los presupuestos anuales de la Secretaría General y determinar la contribución de cada uno de los Países miembros (también para el Tribunal y el Parlamento) e históricamente la Comisión ha repartido estos presupuestos desigualmente, correspondiéndole a Colombia, Perú y Venezuela ${ }^{8}$ un mayor aporte que a Bolivia y Ecuador.

${ }^{8}$ Cuando era miembro de la CAN.

(C) UNED. Revista de Derecho UNED, núm. 16, 2015 
Característica que une al MERCOSUR con la COMUNIDAD ANDINA es la de que ambas subregiones tienen la voluntad de realizar un proceso de integración intenso, de amplio calado económico y comercial, que vaya más allá de la creación de una zona de libre comercio y que lleve a la construcción de un mercado único, con arancel externo común, con libre circulación de los factores de producción, adopción de políticas comunes y coordinación de políticas macroeconómicas.

Ambas subregiones cuentan con Estados Asociados, entendiéndose por tal aquellos Estados que no son Miembros plenos, que no participan en todos los órganos, que no son parte plena de los tratados, ni de sus derechos y obligaciones: su participación y alcance de la misma se define en instrumentos especiales. Los países de la CAN son miembros asociados del MERCOSUR y a la vez los países del MERCOSUR son miembros asociados de la CAN. Chile es miembro Asociado de la CAN y del MERCOSUR, pero no es miembro pleno de ninguna de las dos subregiones. Sería bastante positivo entonces que se piense en la adhesión de Surinam y Guyana a la CAN o al MERCOSUR, sea como miembros asociados o como miembros plenos, a efectos de fortalecer su convergencia hacia la integración suramericana, voluntad que se manifiesta por la participación de estos dos Estados soberanos en la UNASUR.

Sin duda, la dinámica de las subregiones suramericanas, esto es, del MERCOSUR y de la CAN, llevará a constantes movimientos, reformas, profundizaciones, ampliaciones o reducciones, fortalecimientos o retrocesos, de estos procesos de integración.

\section{DERECHO COMUNITARIO ANDINO}

Claramente la Comunidad Andina se ha nutrido en las fuentes del derecho comunitario europeo y por ello la jurisprudencia del Tribunal Andino de Justicia y en general la práctica de los órganos de la Comunidad Andina se inspiran en dicha normatividad. Así por ejemplo, las características del derecho comunitario de la preeminencia o primacía sobre el derecho nacional y la aplicación y efecto directos ${ }^{9}$ han sido consagrados expresamente en el Tratado del Tribunal (art. 3) y previamente el Tribunal de la CAN las había reconocido por vía juris-

${ }^{9}$ SALAZAR MANRIQUE, Roberto, Fundamentos Jurídicos del Derecho Comunitario Andino, En: Integración Económica y Derecho Comunitario, Tribunal de Justicia del Acuerdo de Cartagena, Comunidad Europea, Cámara de Comercio de Bogotá, Memoria del Seminario Internacional, Quito, 1997, páginas 86 á 91. 


\section{La COMUnidad ANDina de Naciones (CAN)}

prudencial, tal y como en su momento sucedió en la Comunidad Europea con las muy famosas sentencias del Tribunal de la Comunidad Europea, Van Gend \& Loos de febrero 5 de 1963, Costa / Enel de julio 15 de 1.964 y Simenthal de marzo 9 de 1.978. Así, a partir de la sentencia de nulidad de junio 10 de $1987^{10}$ y de la sentencia de octubre 26 de 1989 el Tribunal de Justicia desarrolló estos principios jurisprudencialmente en la Comunidad Andina, recogidos luego en el Protocolo de Cochabamba.

La primacía sobre el derecho nacional implica que la normatividad comunitaria es superior al derecho nacional, el que deviene inaplicable en caso de ser contrario a aquella, el efecto directo es la característica que conlleva el que los Estados miembros son vinculados por las normas supranacionales, sin que para ello se requieran llevar adelante todos los trámites que exige una norma internacional clásica para entrar a regir y ser vinculante: firma, aprobación legislativa, ratificación y otros, son todos mecanismos que no operan ante la norma supranacional. La aplicación directa es la característica del derecho comunitario en virtud de la cual las normas son aplicables directamente a los ciudadanos sin que se requiera incorporación de la norma supranacional al derecho interno: la norma comunitaria es directamente aplicable en el territorio del Estado miembro a sus residentes.

El derecho comunitario primario o constitutivo es el conformado por los tratados internacionales suscritos entre los Estados miembros, a través de los cuales se crea la Comunidad, sus órganos y competencias, se trata de normas de derecho internacional clásico. El derecho comunitario secundario o derivado es el emanado de los órganos supranacionales a través del cual se ejercen las competencias comunitarias, las que fueron cedidas por los Estados miembros a la Comunidad.

El artículo 1 del TRATADO DE CREACIÓN DEL TRIBUNAL DE JUSTICIA DE LA COMUNIDAD ANDINA determina las fuentes del derecho comunitario andino:

«Artículo 1. El ordenamiento jurídico de la Comunidad Andina comprende:

a) El Acuerdo de Cartagena, sus Protocolos e Instrumentos adicionales;

b) El presente Tratado y sus Protocolos Modificatorios;

c) Las Decisiones del Consejo Andino de Ministros de Relaciones Exteriores y la Comisión de la Comunidad Andina;

${ }^{10}$ Gaceta oficial N 21 julio 15 de 1987. 


\section{d) Las Resoluciones de la Secretaría General de la Comunidad Andi- $n a ; y$,}

e) Los Convenios de Complementación Industrial y otros que adopten los Países Miembros entre sí y en el marco del proceso de la integración subregional andina.»

Otro punto de certeza jurídica es que en la CAN no hay propiamente políticas comunes, es decir, de adopción de estas mediante normas comunitarias y de ejecución de las mismas por parte de las autoridades supranacionales, bien directamente o bien con la cooperación de los Estados, por cuanto así no se pactó en los Tratados, a más de que no existe en la CAN un presupuesto de recursos propios que permita no solo el funcionamiento de los órganos, sino principalmente la inversión para la ejecución supranacional de las políticas comunes; existen sí unas denominadas "políticas comunes» pero que en realidad son ejecutadas por cada Estado, aunque siguiendo los parámetros muy generales que da la normatividad andina como es el caso de la política común de fronteras e integración física (art. 104 Acuerdo de Cartagena), la política exterior común (art. 50 del Acuerdo de Cartagena) y la política comercial común (art. 54 del Acuerdo de Cartagena), las que requieren de la confluencia de la voluntad de todos los Estados miembros, lo que explica la gran dificultad en realizarlas, fenómeno éste que no es exclusivo de la CAN ${ }^{11}$. Por ello, la práctica ha demostrado que las políticas comunes que pueden ser adoptadas con el voto de la mayoría y no por unanimidad o por consenso, son las que han logrado llevarse adelante, como es el caso de la política agrícola común europea.

También encontramos que los llamados «programas»y «proyectos», ampliamente contemplados en el Acuerdo de Cartagena, no son propiamente de naturaleza supranacional: se rigen por la confluencia de actividades nacionales y supranacionales, la armonización de políticas nacionales y no la adopción de una política común, a más que se ejecutan preferentemente por los Países (ver por ejemplo art. 87 del Acuerdo de Cartagena) y no por autoridades supranacionales (aunque algunos órganos comunitarios, en especial el ejecutivo, pueden, realizar también actividades, como se contempla por ejemplo en el art. 69 del Acuerdo de Cartagena), se basan en la cooperación y coordinación de los Países entre sí en torno a sus Planes de desarrollo y en la armonización de sus políticas económicas y sociales (arts. 53 y 54 del Acuer-

${ }^{11}$ Piénsese por ejemplo en la dificultad de adoptar en la Unión Europea la Política Exterior y de Seguridad Común PESC, regida más por el derecho internacional que por el derecho comunitario y la que para su adopción requiere de la confluencia de la voluntad de los estados miembros, lo cual ante las recurrentes crisis internacionales, se ha mostrado como impracticable. 


\section{La COMUnidad ANDina de Naciones (CAN)}

do de Cartagena), se regulan por normas andinas pero sometidas en realidad a la voluntad de todos y cada uno de los cinco Estados miembros, por lo que sólo nacen a la vida jurídica y son vinculantes para los Estados en la medida en que estos así lo quieran (art. 54, art. 58 y literal c art. 26 del Acuerdo de Cartagena); se trata entonces de armonización en Programas y Proyectos en los respectivos Planes de Desarrollo de cada País, los que son leyes nacionales, sin olvidar además que la Planeación en las economías de mercado es simplemente indicativa y no obligatoria para el sector privado, de donde se concluye entonces que esas normas tampoco son vinculantes para los particulares.

También se encuentran los convenios que dos o más Estados miembros pueden celebrar entre sí, convenios complementarios a los Tratados andinos, cuáles pueden ser los «convenios de complementación industrial» (arts. 64 y 65 del Acuerdo de Cartagena) a más de otros que pueden ser identificados como instrumento jurídico idóneo a la luz de los Tratados, alternativo a las decisiones de órganos comunitarios de representación de los gobiernos, del actuar de los Estados en el desarrollo comunitario, cual podría ser el caso del capítulo XVI del Acuerdo de Cartagena sobre «cooperación económica y social».

Debemos aproximarnos aquí a la noción europea de derecho complementario: "Por derecho complementario se designan aquel conjunto de fuentes convencionales cuyo origen se encuentra en los acuerdos interestatales entre los Estados miembros, pero cuyo objeto se sitúa en el campo o prolongación de los objetivos definidos por los Tratados; en este sentido amplio y por razón de sus fines, se considera Derecho comunitario. No obstante,... por oposición al derecho derivado o al derecho nacido de los compromisos exteriores de la Comunidad, el derecho complementario no resulta del ejercicio de las competencias propias de las instituciones comunitarias. Por contra su nota característica reside en que los Estados miembros, para superar las limitaciones impuestas por el principio de atribución y suplir de algún modo la ausencia de competencias a nivel comunitario, actúan en la esfera de ámbitos propios de la competencia nacional considerada y recurren a su capacidad de compromiso internacional, para adoptar este tipo de actos conforme a las reglas del régimen convencional. En esa medida,..., el derecho complementario mantiene, por razón de su origen y su naturaleza, relaciones específicas con el ordenamiento jurídico comunitario. Básicamente, el derecho complementario y el derecho comunitario se encuentran en relación de compatibilidad; de ese modo se presume que los Estados miembros al actuar por vía de decisiones de los representantes de gobierno reunidos en el seno del consejo o de convenios comunitarios no han violado los Tratados, y han respetado las siguientes reglas: en los ámbitos de competencia

(C) UNED. Revista de Derecho UNED, núm. 16, 2015 


\section{RicARdo Schembri CaRRASQUilla y CAYETANo NúÑEZ Rivero}

comunitaria exclusiva el derecho complementario no tiene cabida; en los ámbitos de competencia compartida por la Comunidad y los Estados miembros el principio que rige es la prioridad del derecho derivado; en los ámbitos de competencias nacional exclusiva los actos de las instituciones no pueden intervenir, siendo idónea la vía del derecho complementario. Dos son las fuentes de derecho complementario mencionadas que examinamos y que completan los Tratados comunitarios, por la vía diplomática o internacional: 1) decisiones y acuerdos de los representantes de los gobiernos de los Estados miembros reunidos en el seno del Consejo; 2) por un lado, los convenios complementarios concluidos por los Estados miembros en virtud del artículo 220 TCEE y más allá de esta disposición otros convenios concluidos por los Estados miembros con el fin de realizar los objetivos de los Tratados en otras materias conexas.» ${ }^{12}$

Así las cosas, entenderíamos que la técnica jurídica aconsejable es precisamente que cuando la Comunidad Andina ejerza sus competencias propias, esto es, las competencias normativas exclusivas y las competencias para la construcción y defensa del mercado común, la libre circulación de bienes y servicios y la unión aduanera, se aplique el inciso $1^{\circ}$ del art. $3^{\circ}$ del Tratado del Tribunal, esto es, que las Decisiones deben ser directamente aplicables en los Países miembros, es decir, que la norma comunitaria tenga plenamente las características de efecto directo, aplicación inmediata y primacía sobre el derecho nacional: es lo que ocurre en materia de propiedad industrial, libre competencia, empresas multinacionales andinas, inversión extranjera, libre comercio, unión aduanera.

Por el contrario, cuando la CAN carece de competencias propias y su función es más de coordinación para el actuar de los Estados, que es lo que ocurre con las actualmente vigentes y llamadas "políticas comunes» y los «programas» $\mathrm{y}$ "proyectos», lo aconsejable sería aplicar el inciso $2^{\circ}$ del artículo $3^{\circ}$ del Tratado del Tribunal, es decir, que las Decisiones deberían indicar que requieren ser incorporadas al derecho interno: así por ejemplo los programas y proyectos adoptados por los Países a nivel comunitario andino, requieren ser incorporados a la ley de planeación o ley del plan de cada uno de los Estados miembros. En virtud de que esas políticas comunes, programas y proyectos no son de competencia comunitaria, de allí se deriva la inexistencia de importantes funciones para los órganos andinos: no cuentan con presupuesto de recursos propios (que debe ser consagrado a través de Tratado), no definen anualmente el presupuesto comunitario de inversión (los órganos representativos de los Estados: Consejo y Comi-

${ }^{12}$ ABELLAN, Victoria, et alt, Lecciones de Derecho Comunitario Europeo, Editorial Ariel, segunda edición, Barcelona, 1995, páginas 100 y 101. 


\section{La COMUNidAd ANDina de Naciones (CAN)}

sión), no se ejecutan partidas de inversión el ejecutivo de la Comunidad, esto es, la secretaría General) y no se controla políticamente (Parlamento) ni fiscal o técnicamente (un Tribunal de Cuentas o Contralor, que son inexistentes a nivel andino). Allí radica una enorme diferencia de la CAN con la Comunidad Europea, tal vez la más grande diferencia institucional existente ente los dos procesos de integración.

Volviendo a la perspectiva del derecho complementario, pasa lo mismo con la armonización legislativa, en temas que siguen siendo de competencia nacional, pero que son relevantes para la consecución de los objetivos de la Comunidad (art. 43 literal f Acuerdo de Cartagena).

Se trata en todos estos casos más bien de derecho complementario, el cual como se vio, tiene características propias, aunque se considera que también hace parte del derecho comunitario, el que en este evento se implementa a través de Decisiones de los órganos de representación de los gobiernos, actuando aquí como entes intergubernamentales y no supranacionales, complementadas por las leyes internas que las deben incorporar al derecho nacional.

Ahora bien, cuando de lo que se trata es de convenir acciones conjuntas en el nivel internacional, asuntos en los que se mantienen las competencias de las autoridades nacionales, pero hay impacto o trascendencia para la Comunidad, es decir, cuando no hay competencias atribuidas a la Comunidad, la vía idónea es la celebración de convenios internacionales complementarios entre dos o más Países miembros, los cuales hacen parte del ordenamiento jurídico comunitario (literal e artículo 1 del Tratado del Tribunal de Justicia de la Comunidad Andina): convenios de complementación industrial (arts. 64 y 65 del Acuerdo de Cartagena) y convenios de cooperación internacional en las áreas del capítulo XVI del Acuerdo de Cartagena (arts. 121 a 132), pero sólo cuando las autoridades supranacionales carezcan de las debidas competencias atribuidas en las normas primarias. Igualmente se trata en este caso de derecho complementario, pero implementado a través de convenios internacionales.

Por lo demás, el inciso $2^{\circ}$ del artículo 3 del Tratado del Tribunal puede también ser entendido y aplicado adecuadamente como una fuente jurídica similar a las Directivas de la Unión Europea, cuando estas Decisiones del Consejo, de la Comisión, del Consejo ampliado o de la Comisión ampliada, dispongan en su texto que su desarrollo corresponde al derecho interno mediante su posterior incorporación o transposición por norma nacional, señalando además para ello un plazo para su entrada en vigor en cada País miembro. Se trata en este caso de fuentes normativas que sí son vinculantes para los Estados 
miembros en cuanto al resultado que debe conseguirse, pero que deja a las autoridades nacionales la elección de la forma y los medios; la finalidad de las Directivas es la aproximación entre las legislaciones o las políticas de los Estados miembros y son normas de resultado. ${ }^{13}$

Un punto de certeza jurídica es el que la Comunidad Andina tiene competencias normativas exclusivas y en la medida en que estas se ejerzan efectivamente, las respectivas normas supranacionales hacen inaplicables las normas nacionales: es lo que ocurre en materia de propiedad industrial e inversión extranjera (art. 55 del Acuerdo de Cartagena), empresas multinacionales andinas (art. 56 del Acuerdo de Cartagena) y libre competencia (art. 93 del Acuerdo de Cartagena) a más de contar con las competencias para la construcción y defensa del mercado común, la libre circulación de bienes y servicios, la unión aduanera (arts. 72 a 86 del Acuerdo de Cartagena), mediante la expedición de las normas correspondientes y la activación del sistema de solución de controversias ante los incumplimientos que se presenten.

\section{LAS CONSTITUCIONES NACIONALES ANTE LA SUPRANACIONALIDAD}

Cuando un Estado se hace parte no ya de un organismo internacional clásico sino de uno supranacional, ello implica lo que la doctrina europea ha llamado una atribución de competencias, es decir, que se trata de otorgamiento del ejercicio de competencias derivadas de la Constitución ${ }^{14}$, a más de implicar ello el que el sistema jurídico nacional se hace permeable, se abre a la normatividad supranacional, se abre a este otro sistema jurídico nuevo y autónomo, todo lo cual exige que una norma de la Constitución nacional habilite todo ello: es la llamada cláusula constitucional de apertura o cláusula de supranacionalidad.

Colombia (arts. 226, 227 y 150 numeral 16), Ecuador (arts. 4, 5 y 161 numerales 3 y 4) y Venezuela (art. 153) ya cuentan con estas normas constitucionales, las que dan la base jurídico-constitucional necesaria para la supranacionalidad y el derecho comunitario.

Por el contrario, si bien la Constitución peruana hace alusión a la integración "particularmente latinoamericana» (art. 44 inciso 2), en realidad en dicho país, como tampoco ocurre en Bolivia, no existe la

${ }^{13}$ LINDE PANIAGUA, Enrique et alt, Derecho de la Unión Europea, Marcial Pons Ediciones Jurídicas, Madrid, 1995, tomo I, páginas 267 y 268.

${ }^{14}$ LOPEZ CANTILLO, Antonio, Constitución e Integración, Centro de Estudios Constitucionales, Madrid, 1996, pages. 68 y 69, 101 á 115. 


\section{La COMUnidad ANDina de Naciones (CAN)}

base constitucional necesaria que requiere la supranacionalidad y el fenómeno comunitario.

Ecuador y Bolivia se encuentran en la actualidad insertos en un proceso de transformación jurídica y es bastante probable que las nuevas legislaciones constituciones regulen la supranacionalidad comunitaria.

Se trata, entonces, de consagrar normas que constituyan el fundamento constitucional específico a la supranacionalidad o a la auto, limitación al ejercicio de la soberanía o, lo que es lo mismo, a la atribución de competencias mediante Tratados a un específico tipo de organización internacional (supranacional o comunitaria). Dadas las evidentes dificultades jurídicas que de allí se pueden derivar, lo aconsejable sería el que ambos Estados promoviesen reformas constitucionales que permitan la adopción de la cláusula de apertura constitucional, como una clara decisión nacional y popular de hacerse partícipe en una Comunidad, lo que permitirá superar una real fuente de incumplimientos ante la normatividad de la CAN.

\section{5. ÓRGANOS DE LA CAN}

Como se sabe, conforme al modelo comunitario europeo, existen órganos de la Comunidad en la que los Estados están representados por agentes suyos, los que reciben instrucciones directas del respectivo Jefe de Estado o del Jefe de Gobierno, son pues órganos de representación de los gobiernos: es el caso de los Consejos de Ministros; otros órganos representan al pueblo, a la ciudadanía, cual es el caso de los Parlamentos de integración; y otros órganos, por el contrario, representan específicamente al interés comunitario, a la Comunidad y precisamente por ello les está vedado representar o recibir instrucciones de ninguno de los Estados miembros: deben actuar con total autonomía e independencia (Ejecutivo y Tribunal). De esta diversa composición, surgen los equilibrios de poder y los controles jurídicos que se deben dar en el seno del organismo supranacional que llamamos Comunidad y entre sus respectivos órganos.

Ahora bien, en la Comunidad Andina los órganos de representación de los Estados miembros o Consejos de Ministros son cuatro: el Consejo Andino de Ministros de Relaciones Exteriores (art. 15 Acuerdo de Cartagena), la Comisión (art. 21 Acuerdo de Cartagena), la reunión ampliada de Cancilleres y Comisionados o Consejo ampliado (art. 20 Acuerdo de Cartagena) y la Comisión ampliada (art. 25 Acuerdo de Cartagena). 
También se estima que la reducción del déficit democrático, que es un problema que aqueja a todos los organismos de integración en el mundo, es la vía que acorde con la experiencia histórica de la Unión Europea se recomienda seguir. Nos referimos al hecho jurídico y político de que las normas que adoptan los Consejos de Ministros en el seno de una Comunidad, en cuanto órganos de representación de los gobiernos, resultan ser en el derecho comunitario las normas de mayor jerarquía jurídica después de los Tratados (equivalentes los Tratados a la Constitución en el derecho interno y las Decisiones a leyes en el derecho interno) y esas normas que expiden los Consejos de Ministros a nivel supranacional desplazan y hacen inaplicables a las leyes nacionales (y otras normas de inferior jerarquía en el derecho interno), leyes estas aprobadas por órganos de representación popular y origen democrático, cuales son los Congresos nacionales: ello por supuesto implica una incongruencia democrática. Por ello, la tendencia es la de fortalecer a los Parlamentos de los organismos de integración y estos se fortalecen de dos maneras, que deben realizarse simultáneamente: A) legitimándolos democráticamente al pasar a ser de elección popular directa; B) dotándolos de importantes funciones a nivel comunitario, cuales son las de actuar como colegisladores de los Consejos de Ministros, cada vez en más materias, la de ejercer control político sobre el ejecutivo supranacional mediante el voto de confianza y el voto de censura y la de ser la máxima autoridad en la aprobación del presupuesto anual de la Comunidad.

En consecuencia es muy acertado institucionalmente el que se siga implementando la elección popular directa del Parlamento Andino, acorde con el Protocolo adicional o con las leyes nacionales que la implementan y que en todo caso se dé plena aplicación al vigente literal e del artículo 43 del Acuerdo de Cartagena, el que establece como atribución del Parlamento Andino el participar en el proceso de generación normativa mediante "sugerencias», esto es que no son vinculantes para los respectivos Consejos de Ministros. También se recomienda una reforma primaria o de los Tratados, que dote al Parlamento Andino de algunas de estas funciones indicadas, entre ellas, que en algunas materias no simplemente dé sugerencias sino que actúe como un verdadero colegislador. La representatividad de los Parlamentarios haría más legítimas las normas andinas y ello redundaría en pro de su cumplimiento. Todo ello sin menoscabo de la iniciativa normativa con que cuentan los Estados y la Secretaría General, en cuanto ejecutivo de la Comunidad Andina.

Por último, si bien los Tratados actualmente no consagran controles políticos robustos, como los que implicarían el ejercicio del voto 


\section{La COMUNidAd ANDina de Naciones (CAN)}

de confianza y del voto de censura por parte del Parlamento Andino ante el ejecutivo comunitario, es decir, ante la Secretaría General, sí existe un mecanismo idóneo de control que permite la activación de un muy importante escenario de actuar interinstitucional: nos referimos a la presentación por parte de la Secretaría General de una evaluación e informe anual sobre la aplicación del derecho comunitario y el cumplimiento de los objetivos supranacionales (art. 29 literal e del Acuerdo de Cartagena), lo cual implica un informe sobre las competencias efectivamente ejercidas por los órganos de la Comunidad, lo actuado en el sistema de solución de controversias por la Secretaría General y el Tribunal de Justicia, informe y evaluación anual que se deben presentar al Consejo y a la Comisión y, entendemos que con la misma periodicidad, al Parlamento Andino (literal b artículo 43 Acuerdo de Cartagena). Este informe y evaluación anual puede ser un muy poderoso instrumento de prevención de incumplimientos.

En este sentido, el Parlamento Europeo invitó

"a la Comisión a que presente todos los años un informe escrito que recoja el conjunto de las violaciones de los Tratados cometidas por los Estados miembros y que precise qué instancias nacionales han transgredido el Derecho comunitario y en qué estado se encuentra el procedimiento». ${ }^{1}$

«... Los Informes examinan separadamente las infracciones de Tratados y reglamentos por una parte y la aplicación de las directivas por otra. En los informes se incluyen una serie de cuadros estadísticos en los que se indican los distintos procedimientos administrativos y contenciosos, agrupados por Estados y por materias, que se han iniciado con el fin de controlar la ejecución del Derecho. Aunque de poca extensión, habitualmente se presenta un anexo dedicado a la actitud de los órganos jurisdiccionales nacionales en la aplicación del Derecho comunitario... Algunos de los informes dedican apartados a aspectos de gran importancia: la consecución del mercado interior..., el medio ambiente..... ${ }^{2}$

Para la periódica elaboración de este Informe y Evaluación anual, la Secretaría General puede desplegar un permanente monitoreo o seguimiento al cumplimiento y aplicación de la normatividad andina, lo cual puede hacer directamente y/o con el apoyo de los otros órganos del Sistema Andino de Integración (pero por supuesto exceptuados los destinatarios que son el Parlamento el CAMRE y la Comisión), autoridades nacionales competentes, de observatorios universitarios de la integración andina, de asociaciones de juristas o de Ongs y de firmas consultoras.

${ }^{1}$ PE Doc 1- 1052 / 82, Rapport SIEGLERSCHMIDT sur la responsabilité des Etats membres en matatiére d'application du droit communataire, de 10 de enero de 1983.

${ }^{2}$ ORDOÑEZ SOLIS, David, La ejecución del derecho comunitario europeo en España, Editorial Civitas s.a., Madrid, 1994, pag. 125. 
